\title{
Aage Jørgensen
}

\section{H.C. Andersen og Carl Larsson}

Karl Johan Backman var vid sin död nästan klar med sin översättning till svenska av H.C. Andersens sagor (1877). Isidor Törnblom hade däremot bara kommit halvoägs med illustrationerna vid sin död, varvid uppgiften överläts till Carl Larsson. Ett danskt urval med Larsson-teckningar ger anledning att konstatera, att han ofta ligger mycket nära, ja nästan plagierar, de danska illustratörerna Vilhelm Pedersen och Lorenz Frølich.

“Så fik jag i uppdrag att illustrera en svensk upplaga av H.C. Andersens Sagor, det vil säga början var redan gjort av en lungsjuk xylograf, som plötsligt dött. Jeg frågar mig: vilket förlag, som kunnat till ett sådant klassiskt verk välja dylika ynkryggar [arme djævle], som denne och jag!? / Jag rodnar nu i tanken på resultatet. / [..] Jag hoppas att ni ha andra upplagor än dessa på edra bokhyllor..."

Citatet stammer fra den folkekære svenske maler Carl Larssons erindringer (Jag, 1931), og hvad han ser tilbage på er den opgave, som man fik ham til at påtage sig, da Isidor Törnblom afgik ved døden, knap 28 år gammel, og knap nok klar med illustrationerne til første bind af den samlede udgave af de Andersen'ske eventyr, som Stockholm-forlæggeren Hjalmar Linnström ville bringe i stand. ${ }^{1}$ Larsson (1852-1919) var på det tidspunkt 23 år gammel.

Oversættelsen havde været lagt $\mathrm{i}$ hænderne på Karl Johan Backman (1825-74) og lå i det væsentlige klar ved hans død. Ganske vist bandt August Strindberg de sidste sløjfer, men indsatsen var for beskeden til, at den kunne berettige ham til at få sit navn anført i udgaven (det oplyses blot, at oversættelsen er blevet "fullbordad av annan hand"). ${ }^{2}$ Denne kom i 1877 i to bind, Sagor och berättelser, med 500 træskårne illustrationer (207 i bind 1 og 293 i bind 2). Der var for Larssons vedkommende tydeligvis tale om et hastværksarbejde, således som det da også antydes i den dom, som eksperten på området Erik Dal fælder i Udenlandske H.C. Andersen-illustrationer (1975, s. 55): “For den [...] fattige pariserstipendiat Carl Larsson var det ganske vist en smuk opgave at få sin barndoms kæreste læsning at illustrere, men hårdt arbejde, ringe erfaring og private sorger dannede ikke den bedste baggrund for dette tidlige arbejde af den senere så frodige og folkekære maler og grafiker."

Trods Larssons skamrødmen er hans indsats ikke gået i glemmebogen. F.eks. er han med i det team, der står som illustratorer af den såkaldte "Jubileumsupplaga" i oversættelse ved Erik Asklund (1955; fotografisk optryk, 1966-67); hovedmændene dér er dog H.C. Andersens danske "hoftegnere" Vilhelm Pedersen og Lorenz Frølich. Og fornylig er han, i forbindelse med 200-årsjubilæet, her til lands for alvor hentet frem af den relative glemsel, - idet forlaget Hovedland netop har udsendt et udvalg med 29 eventyr - eller rettere: Eventyr, sagn, historier, som der står på titelbladet (uden at det dog bliver ganske klart, hvad "sagn" dækker over). Bjarne Nielsen Brovst har skrevet et ultrakort forord. Han citerer Larssons egen vurdering, men opfatter den som et udslag af den store kunstners beskedenhed. Brovst tror på, at det vil glæde mange, at det "endelig nu er 
muligt at se Carl Larssons illustrationer i en dansk udgave". Familielivsidyllikeren fra Sundborn i Dalarne formår nemlig "at trænge ind i H.C. Andersens helt specielle eventyrunivers, hvor idyl og dæmonisering er tætte naboer".

Denne, som det også hedder, evne til at ramme "eventyrenes underjordiske univers" og udstille "mennesket i dyret og dyret i mennesket", holdes op imod de samtidige danske illustratorers biedermeierudlægning af eventyrene, deres stilfærdige nedtoning af det farlige og uhyggelige. Brovst antyder, at det var Andersens forlægger C.A. Reitzel, som "valgte" Vilhelm Pedersen, men kendsgerningen er nu, at det var Andersen selv, der pegede på ham, og vel at mærke med henblik på den danskfødte Leipzig-forlægger Carl B. Lorcks fire eventyrbind i Gesammelte Werke (1847), den udgivelse, der konsoliderede Andersens europæiske berømmelse og i kraft af de to indledende erindringsbind tillige konsoliderede hans "myte". Det var også Andersen, der i 1859 pegede på Lorenz Frølich som Pedersens efterfølger.

En anmelder (Stig Olesen) opfatter "den samling", som Larsson fik til opgave at illustrere, som værende "blandt de mere kuriøse". Sådan var det ikke, Larsson skulle simpelthen illustrere, hvad Törnblom ikke havde nået. Det foreliggende udvalg skyldes jo ikke Larsson, men er foretaget til lejligheden blandt de af Larsson illustrerede tekster. Af hvem? Ja, det fremgår desværre ikke, lige så lidt som det fremgår, hvad der er tekstgrundlaget. Formentlig er det Erik Dals kritiske udgave, hvis fem tekstbind udkom i 1962-66, der er lagt til grund. Et par stikprøver peger $\mathrm{i}$ den retning: "Hyrdinden og Skorsteensfeieren" har (som Dal, der baserer sig på førstetrykket) "arvet fra Oldemoder", hvor f.eks. Erling Nielsens trebindsudgave, Samlede Eventyr og Historier (1961), har "arvet efter Oldemoder", en form, der kom ind i teksttra- ditionen i 1863 og bed sig fast via andenudgaven af Samlede Skrifter i 1879. Senere i teksten har Dal og Hovedland "gesvindt", hvor Nielsen har "hurtigt".

Udvalget omfatter som nævnt 29 af de 156 eventyr. Det er ikke så meget "eventyr", som det er, hvad Andersen efterhånden kaldte "historier" og siden "eventyr og historier". Teksterne, meddelt i kronologisk orden, rækker fra $1845 \mathrm{og}$ frem. Der er altså ikke medtaget tekster fra de seks eventyrhæfter, der var "fortalte for Børn" (dem havde Törnblom taget sig af). De 29 tekster kan næppe heller regnes til de mest "børnevenlige" i Larssons del af Backman-udgaven; talen er langthen om "vokseneventyr".

Bjarne Nielsen Brovst anfører i forordet, at Sverige og Andersen er "en god kombination". Det er korrekt, at digteren flere gange var gæst hinsidan og også flere gange blev hyldet derovre; men det var dog immervæk i Tyskland, at han scorede sin berømmelse. Andersens tidlige skæbne i Sverige er i øvrigt (hvad vi ikke får besked om) skildret af Harald Åström i H.C. Andersens genombrott $i$ Sverige (1972), der studerer oversættelser og kritik i årene 1828-52; Åströms begrundelse for at standse netop dér er, at han så kan få Sverige-bogen og det første hæfte Historier (på svensk: Små-historier) med. (Det kan tilføjes, at Ivo Holmqvist til 200-årsdagen har udgivet en artikelsamling til yderligere belysning af den gode kombination. ${ }^{3}$ )

Brovst nævner forelskelsen i Mathilde Barck og betagelsen af Jenny Lind. Men han skriver intet om det betydningsfulde venskab med romanforfatteren Fredrika Bremer, som Elisabeth Hude har skildret så fortræffeligt i Fredrika Bremer og hendes venskab med H.C. Andersen og andre danske (1972). Formentlig har han slet ikke villet anføre bogtitler, men det er synd således at skubbe solid forskning ud i mørket. Jeg tør godt anføre yderligere et par stykker. Allerede i 1925 
skrev Astri Heimer en bog om Den danske sagodiktaren i Sverige och bland svenskar, og i 1931 fulgte Vagn Børges afhandling August Strindberg og H. C. Andersen. ${ }^{4}$

Hvad angår Mathilde Barck-forelskelsen, så er den beskrevet bl.a. af Elias Bredsdorff $\mathrm{i}$ Anderseniana, 1975. Og hvad angår Jenny Lind-betagelsen, så har den givet anledning til adskillige bøger og artikler, senest Bente Kjølbyes Kærlighedens mange ansigter (2002), der også inddrager Felix Mendelsohn-Bartholdy. Arvestorhertugen af Sachsen-Weimar havde som bekendt en plan om at knytte Andersen og Lind nært til sit hof, så hans lille rige kunne blive et nyt kulturelt kraftcentrum.

Det er al ære værd, at Brovst bruger otte linjer af sit forord til at bringe de danske illustratorer Pedersen og Frølich på bane. Sagen er, at unge Larsson stjal med arme og ben fra dem. Eller med Erik Dals nænsommere formulering: "kunstnerne [altså også Törnblom] låner hos forgængere og virker ikke inspirerede". Når man først har fået øjnene op for dette forhold, begriber man tilfulde, at erindringsbogen ser tilbage på opgaven med blandede følelser. Ikke nok med, at det er de samme situationer, som illustreres, men det sker også ofte på en sådan måde, at man må tale om plagiat. Man kan forvisse sig herom ved minutiøst at sammen-
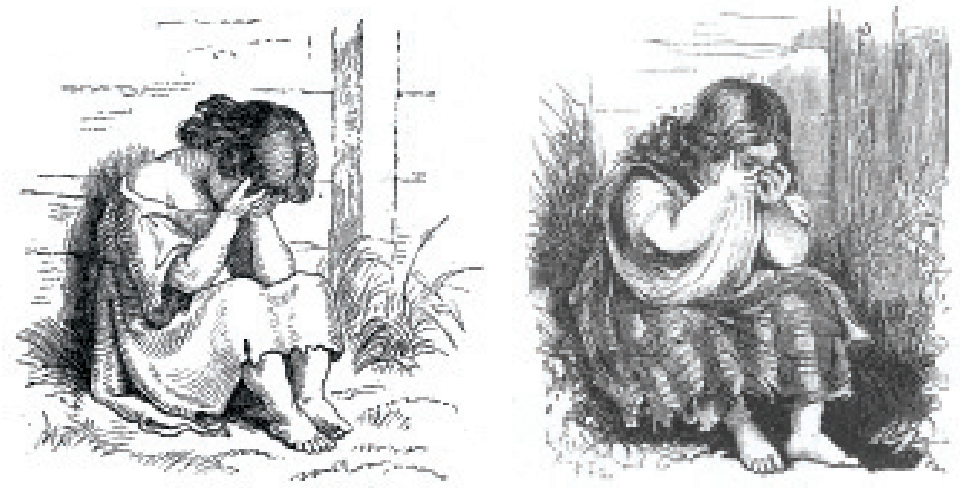

Frølichs illustration till berättelsen Hjärtesorg till vänster och Carl Larssons något mer välgödda barn till höger. ligne Larssons illustrationer til de udvalgte eventyr og Pedersen/Frølichs illustrationer til de samme eventyr i Erling Nielsens nævnte udgave. Den gengiver for Pedersens vedkommende de oprindelige blyantstegninger, nu i H.C. Andersens Hus, - mens man tidligere (også i den nævnte Asklund-oversættelse) gengav tegningerne, som de fremtrådte $i$ de ældste udgaver (hvortil de blev skåret i træ og trykt fra stokkene). Selv var Pedersen ikke just lykkelig over den hårdhed, som ved træsnidernes mellemkomst blev tilført hans illustrationer i Lorcks tyske udgave. For Frølich stillede sagen sig en smule anderledes; han skitserede med blyant, men bearbejdede skitserne med tuschpen.

Det tjener intet formål her at eftergå forholdet mellem Pedersen/Frølich og Larsson i detaljer. Blot nogle eksempler. Madammen med moppen i "Hjertesorg" er knap til at skelne fra Pedersens madamme (bortset fra, at der - som ofte ellers - har fundet en spejlvending sted), og den lille pige på moppens grav er også tydeligt nok gjort efter danskerens tegning. Den store historie om "DyndKongens Datter" får både hos Larsson og Frølich 20 tegninger, og kun på et par punkter er der motivisk varians (således på tegningen af den i Vildmosen landede ægyptiske prinsesse, hvis nøgenhed Larsson lader sivplanterne camouflere).

"Ane Lisbeth" får 12 tegninger hos Larsson mod ni hos Frølich; et par situationer er opfattet forbløffende ens, således titelpersonens drøm, hvor jordiske kvinder drager hende nedad, mens en engel drager hende opad (og just til engle er Larsson ikke god). 

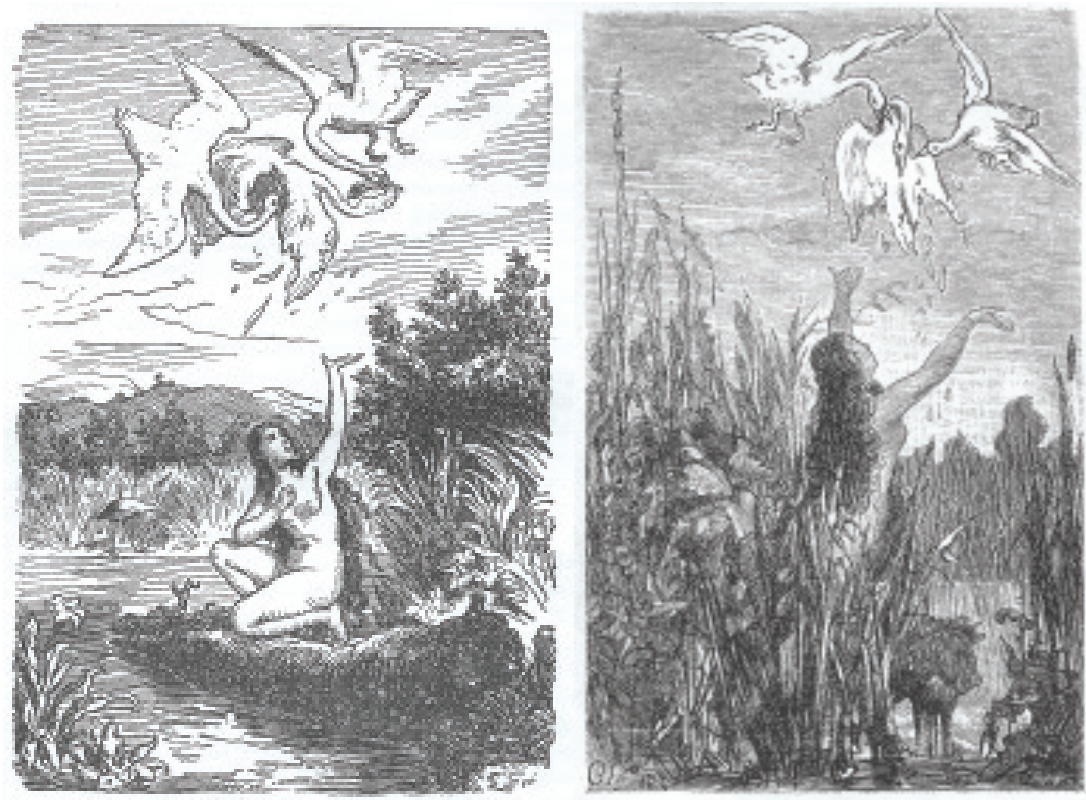

Den danska originalteckningen av Frølich till vänster och Carl Larssons mer dolda kvinna till höger. Illustrationer till Dykungens dotter.

Der er vitterligt motiver, som Larsson er ene om, men det er undtagelsen, hvor det kunne have været det tilstræbte. Gennemgående elaborerer og dramatiserer han dog de overtagne motiver, skraverer mere og "supplerer" baggrunden. Pigen på moppens grav har flere folder i sin pjaltede kjole, end tilfældet er hos danskeren. Hvor Andersen i "Skarnbassen" lader "nogle unge Piger" befri det stakkels dyr, som skarnsknægtene har bundet og sendt til søs i en træsko, tegner Frølich to piger, mens Larsson presser fem ned i den selvsamme båd; men saksen, som en af dem bruger til at klippe skarnbassen fri med, er præcist den samme! Til "Tolv med Posten" har Frølich én tegning af de tolv månedsrepræsentanter, der stiger ud af postvognen, mens Larsson fremviser dem i fire grupper; alligevel ses det, at Larsson har studeret Frølich-tegningen nøje. Larssons børn er gennemgående lidt federe end danskernes. I "Nissen hos Spekhøkeren" damper grødfadet lifligere, i "Noget" brænder den fattige kones hus voldsommere.
H.C. Andersens eventyr vrimler med situationer, der ligefrem lokker illustratorerne til. Man tænke f.eks. på sluttableauerne i "Skyggen" og "Hvad Fatter gjør, det er altid det Rigtige". Larsson varierer (Pedersens version af) kongedatterens poseren på altanen med Skyggen ved sin side såvel som (Frølichs version af) bondemandens hjemkomst med de rådne æbler, - bl.a. får han plads til en grim ælling. Men hvad angår "Klokken", så dropper han mødet mellem kongesønnen og den fattige dreng, der ad hver sin vej når i mål og favner hinanden i naturens og poesiens store, hellige kirke. ${ }^{5}$

Friest er Larsson nok i illustrationerne til "Lygtemændene ere i Byen, sagde Mosekonen", "Sølvskillingen" og "Marionetspilleren".

I ét tilfælde (s. 161) burde man nok have opsøgt et andet forlæg, da det anvendte tydeligvis er beskadiget. Og så har "Pebersvendens Nathue" en passus om den gamle Anthon, der på dødslejet fremtænker en helgeninde "foran hans Seng i den ringe Træ- 
bod", hvilket i tekstcitatet under den tilhørende tegning er blevet til “Træbord" (s. 72). Korrektøren har tillige betvivlet, at Anthon "imorgen" ville være "karsk og rigtig oppe igjen" og i stedet lanceret "rarsk" (s. 73)!

Brovst Nielsens reference til Émile Zola ("dyret i mennesket") skal næppe forstås som en pointering af, at Larsson som H.C. Andersen-illustrator er naturalist. Den senere så umådeligt berømmede skildrer af hjemlig og familial harmoni er unægtelig god til at tegne dyr, men samtidig mindre god til at få "liv" i sine menneskelige figurer, uanset om de skal være "dyriske" (altså dæmoniske) eller ej. Hvorom alt er: da han satte sig til rette i erindringsstolen, måtte han med rette rødme og håbe på, at læserne havde andre udgaver at ty til. På den anden side yder Hovedland-udgaven $(17 \times 25 \mathrm{~cm})$ hans illustrationer større retfærdighed end den temmelig kompakte svenske original (13 x 18 $\mathrm{cm})$; ofte er der tale om en betragtelig forstørrelse, f.eks. fra 6 til $12 \mathrm{~cm}$ i bredden. Prisen for de 336 sider er i øvrigt rimelig: kr. 248,-.

\section{Noter}

1. Frans Oskar Isidor Törnblom, f. 24.11.1848, d. 1876 (dato ukendt). Anderseniana-registerbindet (1999) oplyser: “o. 1880”. If. Svenskt konstnärslexikon, bind 5, 1967, s. 494, var han "särskilt känd" som xylograf. Andersenillustrationerne karakteriseres som "rätt skickligt tecknade".

2. Strindbergs medvirken ved oversættelsesprojektet blev af så stor betydning for ham, at han i sit bidrag til Politiken's enquete ved 100årsdagen i 1905 underskrev sig “A. Strindberg, Elev af H.C. Andersen”. Enquetebidraget (hvoraf det fremgår, at det var den vordende digters venskab med Carl Larsson, der bragte ham til fadet) er optrykt bl.a. i Nationalupplagan av August Strindbergs Samlade Verk, del 71: Essäistik, journalistik och annen prosa 1900-1912, Stockholm 2005, s. 75-77. Om oversættelsesindsatsen: Anton Blanck, "En okänd Strindbergsöversättning från H.C. Andersen", Samlaren, n.f., bind 1, 1920, s. 167-68; Margareta Westman, "När Strindberg översatte H.C. Andersen", i Gunnel Engwall \& Regina af Geijerstam (red.), Från språk till språk. Sjutton uppsatser om litterär översättning, Lund 1983, s. 151-67.

3. Ivo Holmqvist (red.), H. C. Andersens underbara resor i Sverige. Göteborg/Stockholm, 2005. 321 s, 4 pl. (Med nye bidrag af: Ivo Holmqvist, Anders Palm, Boel Westin, Vivi Edström, Ulla Lundqvist, Ying Toijer-Nilsson, Inger Litt-

berger, Hans Holmberg, Folke Bohlin, Johan Stenström, Svante Nordin, Sven Christer Swahn og Johan de Mylius; bibliografi af: Aage Jørgensen og Ivo Holmqvist; ældre artikler af: Hellen Lindgren, August Strindberg, Bo Bergman, Göran Lindblad, Anders Österling, Hjalmar Bergman, Hjalmar Söderberg, Adolf Hallman og Jan Olof Olsson.)

4. Om forholdet Andersen/Strindberg generelt og om Sagor (1903) specielt: Göran Lindblad, August Strindberg som berättare. Studier $i$ hans tidiga prosa, Stockholm 1924, spec. s. 37-67; Torsten Fogelqvist, "Andersen och Strindberg. Ett litteraturhistoriskt referat", i hans: Typer och tänkesätt. Litterära utkast, Stockholm 1927, s. 288-303 (opr. i Dagens Nyheter 4. og 7.8.1925); Vagn Børge, August Strindberg og H.C. Andersen, 1931, 146 s.; Signe Fabricius Møller, "H.C. Andersen-stiltræk i Strindbergs Sagor", i: Svensk stil. Studier tillägnade Bengt Hesselman den 21 december 1935, Uppsala/Stockholm 1935, s. 101-10; Boel Westin, "'Hexmästaren'. Strindberg, Andersen och sagotraditionen", Strindbergiana, 1995, s. 183-97; id., Strindberg, sagan och skriften, Stockholm 1998, spec. s. 89-115; Erik Svendsen, "Strindberg in Wonderland. Refleksioner om 'Sagor'", Nordica, bind 17, 2000, s. 37-50.

5. Muligvis er det kun i den danske udgave, denne situation er udeladt. 